\title{
3. Post-disaster recovery is a marathon, not a sprint The need for a state-sponsored recovery scheme
}

\begin{abstract}
This study explores the recovery experiences of survivors of a flash flood event, five years after a natural disaster in South East Queensland. In-depth interviews were conducted with 33 of the original cohort of 120 postdisaster interviewees who experienced sudden traumatic bereavement and/or their own near-death experience. The data reveals that many of the survivors and rescuers were in worse - or far worse - situations than they had been in the weeks and months immediately after the disaster. Interviewees identified the worsening of their situation as being caused by systems failures by civil authorities, health care systems, welfare programmes and the insurance industry. Further research is recommended to assess the needs of people affected by natural disasters and the viability of a state-funded recovery scheme that could expedite personal, family and community recovery. The proposed scheme is based on the Queensland WorkCover scheme that scaffolds recovery and return to work for injured workers.
\end{abstract}

Keywords: Australia, community recovery, economic recovery, natural disasters, disaster recovery, personal recovery, policy

\section{AMANDA GEARING \\ Queensland University of Technology}

\section{Background}

HIS RESEARCH was initiated to document individual, family and community recovery that took place in the five years after a deadly 2011 flash flood in the South East Queensland. The 10 January 2011 disaster suddenly caused a path of swift-water destruction down the eastern edge of the Great Dividing Range and across the coastal plain. Without warning, it killed 23 children and adults and swept away homes, roads and bridges, bringing down power lines as it roared down the river systems. In 2016, interviews were conducted with survivors and rescuers in the eight locations that had been affected. The districts varied in altitude, population and geography. The largest was a regional city at an altitude of 700 metres above sea level while the smallest was a sparsely- 
settled rural district. The other locations affected were rural districts or towns in the foothills of the mountains or on the coastal plain. The data indicates that existing disaster recovery services have been inadequate to effect recovery for some individuals and their families. Further research is recommended to establish the cost-benefit of improved post-disaster support for people who are bereaved or rendered homeless, injured or traumatised by natural disasters.

The range of difficulties experienced by the interviewees included bereavement of a spouse, child or relative during or post-disaster; delayed shock due to their own near-drowning; shock regarding the near-deaths of family members; loss of employment; loss of physical ability to return to their pre-disaster employment; loss of community cohesion; ongoing trauma triggers of the disaster event; inadequate access to psychological care; being 'trapped' in the disaster zone due to depressed property values; and being unable to afford highly-inflated house insurance premiums.

The key finding of this primary research is that personal and community recovery are far more slow and complex than previously understood. Current post-disaster support mechanisms are not satisfactory to meet complex individual, family and community needs. Improvements are recommended that would scaffold recovery, especially for those people who are traumatically bereaved, made suddenly homeless, injured or rendered unemployable by the disaster. A scheme modelled on workers, compensation is suggested as a possible option to consider.

The data obtained from the original semi-structured in-depth interviews became the basis for a 55-minute radio documentary, The day that changed Grantham (Gearing, 2011) and a non-fiction book published in January 2012 by the University of Queensland Press (Gearing, 2012c). The 2016 interview data was used to update and republish the book under a revised title, The Torrent: A True Story of Heroism and Survival, in January 2017 (Gearing, 2017). The recorded interviews, photos and videos were acquired by the Queensland State Library and form an archive of the disaster (Gearing, 2012a).

\section{Aim}

The research aimed to discover what happened to the survivors of the 2011 disaster and whether they had recovered; what happened to the rescuers and whether they had recovered. It also aimed to discover what happened to the towns and districts and whether they had recovered - and if not, what improvements were needed to enhance the possibility of recovery for individuals and communities.

\section{Literature review}

Large-scale natural disasters such as floods, cyclones, tornadoes, wildfires, earthquakes, tsunamis and tidal surges have increased the need for well-prepared 
counter-disaster and post-disaster recovery agencies (Boulter, Palutikof, Karoly, $\&$ Guitart, 2013; Letcher, 2009). Flash floods kill more people than any other type of natural disaster - an average of 5,000 people around the globe each yearand have the highest mortality rate of any natural disaster (Hydrologic Research Center, 2018). Recovery of people, communities, businesses and economies after disasters is acknowledged to be a 'complex, nonlinear process that involves physical as well as social, economic, and institutional recovery dimensions' (Johnson \& Hayashi, 2012). Yet policy developed to manage recovery remains under-developed. Even as recently as 2010, a study after Cyclone Katrina found that 'the policy and administrative processes of recovery from catastrophic events have not been well understood, and ... the lack of clear policy design ... has hindered recovery' especially in large-scale disasters (Comfort, Birkland, Cigler, \& Nance, 2010, p. 669).

Media coverage has focused primarily on economic damage rather than psychological damage - even though the latter can be more long-lasting (Cox, Long, Jones, \& Handler, 2008). In the 2000s several studies found that recovery is never a return to pre-disaster conditions but that the disaster leaves long-lasting effects (Alesch, 2005; Daniels, Kettl, \& Kunreuther, 2006). Johnson and Hayashi (2012, p. 227) emphasise a 'new normal' in their definition of recovery:

Recovery is a complex, multidimensional, nonlinear process. It involves more than rebuilding structures and infrastructure; rather, it is about people's lives and livelihoods. The process has no clear end point and there is not necessarily a return to what existed before.

Although theorists have argued over the merits of physically-oriented or process-oriented recovery plans (Johnson \& Hayashi, 2012), both types of analysis focused on macro systems rather than on individual survivors. It was not until 2010 that researchers observed the importance of local empowerment; of innovative organisation; and leadership, in overcoming bureaucratic impediments to recovery and reducing vulnerability by rebuilding improved infrastructure (Garnett \& Moore, 2010).

The recovery time differs from event to event but researchers have observed that recovery takes much longer than was previously believed. It has only been in the past decade that theoretical models have been advanced to conceptualise disaster recovery (Johnson \& Hayashi, 2012) —and even then the period of recovery time under scrutiny was relatively short. The first US study that examined community recovery after 14 disasters was restricted to the period from 12 months to 24 months post-disaster (Rubin, 1985). Haas et al (1977) found that, although structural rebuilding occurred relatively quickly in the weeks and months after disasters, rebuilding also continued from two to ten years post-disaster and 
incorporate recovery of individuals households, businesses and neighbourhoods (Mileti, 1999; Rubin, 1985).

'Life recovery' has been tracked over ten years in a longitudinal study in Japan that followed victims of the 1995 Kobe earthquake. The study found life recovery occurred in seven stages: provision of housing; restoration of social networks; reconstruction; preparedness for future disasters; maintenance of mental and physical health; financial stability; and government assistance (Tatsuki, 2007). Of these different stages, the most important element of recovery was found to be housing, closely followed by the re-establishment of social ties and land use planning (Tatsuki, 2007).

The effects on physical and mental health of people who choose, or who are forced, to relocate after disasters was scarce and the findings were inconsistent, even in the 2000s (Uscher-Pines, 2008). Relocation of the worst-affected town in the Lockyer Valley therefore offers early anecdotal evidence that relocation is preferable - and medically indicated - in situations where survivors have faced a near-death experience or the death of family members during a disaster (Gearing, 2017). Gearing (2017) also found that the effects of the disaster were different in each of the eight districts: in some localities people died, while in others no one died; in some localities, local businesses were severely damaged while in others businesses remained open. In some localities roads and communications were disabled while in others these remained functional. Recovery for some communities was therefore quicker and easier than in others where people were missing, infrastructure was destroyed and communications were disabled.

News media interest in disasters is by nature limited to a relatively short time before, during and after an extreme weather event or natural disaster. Reporting of the 2011 flash flood disaster covered the event itself, and the first days and weeks of the clean-up and rebuilding, returning briefly for anniversaries and an Inquiry in 2015. Post-disaster reports proclaimed recovery to be 'normal' when the first new house was completed on the new estate before the following Christmas (Sanders, 2011). At this time, however, many families were still living in makeshift accommodation such as shipping containers, dongas or caravans and even after five years, some people were still not in permanent housing (Gearing, 2017). A longer-term media interest in post-disaster recovery could arguably assist the personal recovery of disaster victims by helping to maintain community awareness and government attention on the evolving needs of those affected. It is hoped that prolonged media attention to the process of recovery may result in research that will indicate how best to scaffold appropriate support to facilitate recovery in future.

Newman and Nelson (2012) have described the cycles of trauma that survivors experience. They identify three cycles of trauma that occur simultaneously in which the survivor vacillates from one extreme to the other over days 
or weeks. In the first cycle, the survivor feels a strong desire to 'approach' the trauma, to find out what happened, or feels an equally strong desire to avoid memories of the trauma and avoid all information about the trauma. A second cycle occurs simultaneously in which feelings of resilience are felt whilst at other times experiencing feelings of vulnerability. A third cycle, also simultaneous, is to experience the trauma as something 'other' - an experience that seems to be fragmented or separate from their life while at others time experiencing the trauma as something that has happened to them in their life. Gearing (2017) has found that - in contrast to the practical government support given to injured workers to recover- if a person is injured in a natural disaster, there is much less support available. In this disaster, for example, professional rescuers sometimes required up to six months away from work to recover. However civilians affected by the disaster who carried out life rescues without any warning or any training or any purpose-designed equipment, had no safety net that provided them with counselling, income support or job security (Gearing, 2017).

In addition, disaster survivors who were bereaved, homeless and unable to work had no safety net to provide medical care, housing, income support or job security and were forced to rely on their own resources and charitable organisations (Gearing, 2017). Gearing (2017) also found that during long-term recovery periods, the survivors had to deal separately with multiple medical providers, insurance companies, tradespeople, banks and employers. The financial stress of having to pay a mortgage on their home (that they could not live in) and also pay rent for a house to live in, was rarely affordable in the medium-term. Therefore, instead of being scaffolded to recover, survivors injured in the natural disaster were immediately immersed in a maelstrom of bureaucracy when they could least cope and when they could least afford the extra costs (Gearing, 2017).

This article proposes that consideration should be given to researching the viability of programmes similar to government programmes that assist injured workers. It is envisaged that the programme could facilitate co-ordinated medical care, psychological care, wage support and gradual return to work to provide a quicker, less stressful recovery via a case manager allocated to each family that is severely affected by a disaster. A 'DisasterCover' scheme would also provide access to a legislated support scheme rather than survivors being at the whim of ad hoc emergency allocations of government funding or needing to rely upon funding from public appeals. The cost of such a scheme could be mitigated by adopting a cost-saving aspect of Queensland's WorkCover scheme in which the scheme meets emergency medical, rehabilitation and wage costs and then claims them back, where possible, from the claimant's private medical and income protection insurance. A second benefit of establishing a recovery program is that survivors would deal with one case manager with regard to all aspects of their recovery including housing, health, income support and return to work. 


\section{Method}

This qualitative study used grounded theory to discover the main challenges faced by flood survivors in the five years after the 2011 disaster. The participants represented each of the eight districts affected by the flash flood: Spring Bluff, Murphys Creek, Toowoomba, Withcott, Postmans Ridge, Helidon, Carpendale and Grantham. Qualitative semi-structured interviews were carried out with 30 participants who were rescuers and/or affected residents from the original research cohort of 120 . Not everyone could be contacted for the follow-up interviews. Of the people who were invited to participate in the second interview, almost everyone was willing to be interviewed again in the interests of documenting and recording their post-flood experiences. One additional participant was added to the 2016 group because of his central role in leading the recovery of his local village of Murphys Creek.

The interview method used was the prototype method developed and used in the first round of interviews in 2011. This method is informed by Newman and Nelson's theorisation of how the three dances (cycles) of trauma can better inform reporters who interview traumatised news sources. In this prototype interview method, the interviewee is encouraged to give an uninterrupted narrative of their experience at first, allowing them to find and assemble their scattered trauma memories into a cohesive narrative that they experience as being therapeutic. After the narrative is completed, further questions are asked for clarification.

The interviews canvassed the person's experience and the community's recovery in the five years after the disaster. The data was coded. Subsequent content analysis revealed that participants identified ten major types of barriers that had adversely affected or prevented their recovery.

Although the five-year follow-up interviews were conducted primarily to revise and update a non-fiction book, the richness of the data meant the information was a useful resource having the potential to inform future research that might lead to improvements in emergency responses and disaster recovery. The Queensland Department of the Premier and Cabinet and the University of Queensland Medical School expressed interest in the findings and invited the author to present the findings of the research to selected staff and researchers in 2017.

\section{Findings}

Recovery from the 2011 disaster was relatively quick for some people. Those people who lost possessions but who were not traumatised by the disaster; who remained healthy and had insurance with companies which promptly paid their claims, were able to resume their work, repair or replace their homes and return to a relatively normal life within a few months to a year. However, for those people who were bereaved of one or more family members during or after the flood; or who were traumatised on the day by a near-death experience; or who 


\begin{tabular}{|c|c|c|c|c|}
\hline Places & $\begin{array}{l}\text { Number of } \\
\text { interviewees }\end{array}$ & $\begin{array}{l}\text { Gender } \\
\text { (Male) }\end{array}$ & $\begin{array}{l}\text { Gender } \\
\text { (Female) }\end{array}$ & $\begin{array}{l}\text { Trauma experienced by } \\
\text { interviewees }\end{array}$ \\
\hline Spring Bluff & 4 & 2 & 2 & $\begin{array}{l}2 x \text { near-death experiences } \\
2 x \text { neighbours died } \\
2 x \text { neighbours near-death } \\
\text { experiences } \\
1 x \text { damaged houses }\end{array}$ \\
\hline $\begin{array}{l}\text { Murphys } \\
\text { Creek }\end{array}$ & 5 & 3 & 2 & $\begin{array}{l}3 \times \text { near-death experiences } \\
1 \times \text { discover corpse } \\
2 x \text { life rescue } \\
1 x \text { business destroyed }\end{array}$ \\
\hline Toowoomba & 2 & 2 & 0 & $\begin{array}{l}1 \mathrm{x} \text { life rescue } \\
1 \mathrm{x} \text { wife and son died }\end{array}$ \\
\hline Withcott & 2 & 2 & 0 & $\begin{array}{l}\mathrm{x} \text { life rescue } \\
1 \mathrm{x} \text { flooded business } \\
1 \mathrm{x} \text { flooded house } \\
\end{array}$ \\
\hline $\begin{array}{l}\text { Postmans } \\
\text { Ridge }\end{array}$ & 2 & 1 & 1 & $\begin{array}{l}2 \times \text { neighbour drowned } \\
1 \times \text { near-death experience } \\
1 \times \text { rescue race horses }\end{array}$ \\
\hline Helidon & 8 & 4 & 4 & $\begin{array}{l}\text { 1x life rescue } \\
1 \times 4 \text { life rescues } \\
1 \times \text { farm flooded } \\
3 \times \text { near-death experience } \\
2 \times \text { house and possessions } \\
\text { destroyed }\end{array}$ \\
\hline Carpendale & 1 & 0 & 1 & $\begin{array}{l}1 \times \text { houses and possessions } \\
\text { destroyed } \\
1 \times \text { farm destroyed }\end{array}$ \\
\hline Grantham & 6 & 3 & 3 & $\begin{array}{l}1 \times 28 \text { life rescues } \\
1 \times \text { life rescue } \\
1 \times 3 \text { life rescues } \\
5 \times \text { knew multiple deceased } \\
2 \times \text { house and possessions } \\
\text { destroyed } \\
6 \times \text { near-death experiences } \\
1 \times \text { house swept away }\end{array}$ \\
\hline Total & 30 & 17 & 13 & \\
\hline
\end{tabular}

Note: Interviewees with flood survivors and rescuers, 2016, in the fifth year after the 2011 flash flood disaster in South East Queensland.

lost their ability to work in their pre-flood job; or who had significant and lifethreatening health problems, or whose insurance claims were slow, difficult or 
rejected, the journey was far longer and more difficult. Those who experienced several of these impediments to recovery took longer to recover or had regressed in the five years after the disaster.

The number of survivors and rescuers and next-of-kin interviewed in 2016, their gender and the traumas experienced are summarised in Table 1:

Ten major impediments were identified by participants that slowed or prevented them or their family from making a timely recovery. Each of these is illustrated below by examples from the interview data.

\section{Bereavement during or post-disaster}

The suddenness of the deaths caused by the inland tsunami left next-of-kin deeply shocked. In most cases the homes of the next-of-kin had also been destroyed. In some cases the bodies of next-of-kin are still missing. Three bodies were never recovered despite protracted helicopter searches that combed 131 kilometres of creeks and river banks looking for human remains. There was no established government program to pay for funerals for those killed in the floods leaving families with a high, unexpected cost burden.

A feature of this disaster was that the significant death toll of 13 people who died in Grantham - a town with a population of about 300 people - and the severity of the structural damage to the town, led to the first instance of the Queensland State Government buying land above the flood zone and giving blocks of land in a land ballot to those affected (Bligh, 2011). However it was not the first time a town in Australia has been moved following floods as Bega, Gundagai and Clermont were moved after deadly floods in those towns in the 1800s and 1900s (Coates, 2012).

An inquest into the deaths in the Lockyer Valley flash flood established that the location of the deadliest force and speed of the onset of the flood occurred along the Gatton-Helidon Road, a kilometre north of Lockyer Creek. People in four households, all on a short section of highway, died. These included a mother and her three children and three elderly residents. Fortunately several of the residents in this location were still away on Christmas holidays at the time. The only families which survived in this location were those who received direct individual warning or help to escape. Many who survived by happenstance experienced survivor guilt. Others who struggled in the months and years after the flood with financial, insurance, unemployment, psychological or serious physical health issues, expressed in their follow-up interview that they would have preferred to die rather than endure the five years post-flood.

State government-funded funerals for those who died are a realistic expectation of bereaved families. Income support for those temporarily unable to work and emergency housing for those left homeless would also seem to be reasonable expectations that would scaffold the recovery of those most deeply affected by 
a natural disaster. Further research into how this could be funded and delivered is recommended.

\section{Delayed shock due to their own near-drowning}

Thirty-three of the original cohort experienced a near-death experience on the day of the flood (Gearing, 2012b). Five years on, some of those who had near death experiences had still not attended any counselling. For example, Murphys Creek cleaning contractor Angie Pohl, whose car was swept from a causeway at Murphys Creek, was still recovering from her near-drowning ordeal and her rescuers were still affected by the risks they took to save her.

I was depressed for probably a year after the floods. I think having the depression made me not want to go out, and that was the start of the depression. And although the depression did sort of start easing into the second year, I still don’t want to go out a lot.

Pohl is still affected by how close she came to dying:

My mind does play out what was going to happen if they didn't turn up. That's when I go back to thinking about Matthew and Ian not turning up and where I was going to be in a few minutes' time. I just saw where I was, the big logs that were floating by me and going over the edge of that dam - and that was not far from where I was - and I knew I had no chance. If they didn't come, I knew there was nowhere I could go.

One of Pohl's rescuers, Matthew Eddison, had counselling after the flood but he was still traumatised by the danger he put himself in, even though the rescue was successful. It has taken five years for him to be able to acknowledge the severity of the risks he took:

I risked my life to save Angie. I was thinking so strongly about getting her out of there. I didn't hesitate at all. She's alive today. I must think of the results.

A Grantham businesswoman is still affected by the suddenness with which her life and the lives of three of her children were in danger:

We're trying get back to normal, but normal is never normal. Life as you know it changed on that day. You know that one second your life is normal and then how quickly things can change. I scan all the time. I scan rooms for the exit. I scan terrain in case something happens-which is the quickest way to escape?'

A former Grantham businessman also still struggles with intrusive memories of being trapped in his service station and scrambling to the roof. His distress is 
triggered by running water, rain and being in a room from which he can't see out.

The importance of access to publicly funded psychological care beyond the ten visits allowable under the current Medicare system is warranted, especially for the next-of-kin of people who die in a natural disaster. Further research is recommended to establish how this health care could best be provided.

\section{Shock following near-deaths of family members and friends}

The five years post-flood have been particularly difficult for those people whose lives were at risk during the event and for those who were suddenly bereaved of family and friends. Many whose lives were at risk also knew people who did not survive. For example, a mother who fled her home with three children and survived by running along the railway line ideates on how close they all came to dying that day:

I allowed somebody in those split seconds to make the decision [to leave in a vehicle] for me. That's hard for me sometimes. I'm glad it worked out like it did and it was the right decision but sometimes it makes me angry to think I wasn't able to make a conscious decision - and only a matter of seconds and we would have all drowned in that vehicle.

Several of the survivors spoke of the 'near miss' they had with death. For some people this became an incentive to live every day with renewed gusto, while for others the near miss reinforced for them the fragility of life and left them feeling more vulnerable. Access to free government-funded counselling would seem to be a useful commitment of public funds to improve the prognosis and enhance the speed of recovery of anyone who confronts a near death experience during a natural disaster. Possible income support and an option to have a staged return to work could also be considered. Research is recommended to ascertain what medical care is needed and the most optimal method by which to make it available and accessible.

\section{Loss of employment and financial hardship}

Several flood survivors were unable to return to their previous employment because their workplace had been flooded or because they were traumatised by memories of the flood when they returned to the disaster zone. For example, Grantham service station owner Marty Warburton, who had narrowly escaped with his life and climbed to his roof, stated at his five-year follow-up interview that he wished that he had cut his losses and moved away from Grantham immediately after the flood. Staying to rebuild his business meant he remained in the line of fire for a subsequent flood in 2013 which destroyed his service station a second time. He rebuilt again only to have his business destroyed a third time, this time by a tornado, in January 2014.

Others suffered quite extreme financial hardship and relied on charities for food, clothes and shelter for months to years after the flood. For example, an 
elderly couple who were in their house when it and all their possessions were swept away relied on public donations of clothing, furniture, household appliances and kitchenware to re-establish a home.

Loss of employment due to a natural disaster and financial hardship directly attributed to a natural disaster might be considered beyond the control of individuals to finance, at least until they are able to claim on their personal house and contents insurance, income protection insurance and health insurance. State-funded emergency funding to scaffold as speedy a recovery as possible for disaster victims, should be considered. Research is needed to quantify the needs of people who are unable to continue in their employment following disasters to find viable alternatives to scaffold their recovery.

\section{Loss of physical ability to return to pre-disaster employment}

People who are injured at work in Queensland are eligible to claim on WorkCover, a government funded program that assists workers to recover and return to work. People injured in disasters, however are not eligible for the same assistance to pay for medical care, rehabilitation and retraining if necessary, in order to maintain their financial independence. Several of the families affected by the 2011 disaster had never drawn any welfare payments and refused or resisted charitable help or government help to which they were entitled. People who were injured and therefore became unable to continue their careers faced significant challenges in addition to the loss of their house and possessions, placing them in very vulnerable financial situations. For example, a Grantham nurse who broke her wrist the day before the flood and damaged it again the next day when she rescued her husband, was left unable to return to her nursing career. Despite being self-supporting all her life, the flood left her dependent on her married adult daughter for housing and access to a car. At 61, she was required to retrain and find another job.

Workers injured during natural disasters to the extent where they cannot return to their former work should be able to expect financial support to replace their income while they retrain so that they can re-enter the workforce. Provision of short term retraining and income support are a reasonable investment in the recovery of a person so that they can return to financial independence. Further research is needed to investigate the viability and cost-benefit of public funding for people who are injured in disasters.

\section{Loss of community}

In the small rural district of Spring Bluff, a couple died when they were swept from their home and drowned. Almost all the other residents in the street sold their properties and left the area. The 18 residents who had lived there before the flood were reduced to three after the flood. Two of the three residents who remained in the fifth year after the flood were intending to leave as soon as possible. Those who 
sold to escape the disaster zone sustained heavy capital losses on their investment.

The residents affected at Spring Bluff bought properties zoned for rural residential purposes. It would seem reasonable that the large capital losses they sustained should be, in part, born by the local government which zoned the land as suitable for residential housing. Placing responsibility on the authority responsible will hopefully help to ensure care is taken that land approved for residential housing is not at risk of life-endangering flooding. Further research is recommended to ensure land re-zoned for residential housing is not subject to fast, destructive and potentially fatal floodwater.

\section{Ongoing trauma triggers}

Twenty of the 30 people interviewed in the fifth year after the flood reported experiencing ongoing traumatic memories such as continuing to hear the sound of rushing water, smelling the foetid aroma of the mud or flashing back and feeling anxious when they hear the sound of helicopters. For some people the trauma triggers occurred only in the geographic area of the flood zone while for others the triggers occurred in any location. For example, Postmans Ridge resident Rod Alford experienced triggers and flashbacks even when he was in a different location such as an interstate city. He was also so distressed by heavy rain, thunder and lightning that he gets out of bed and puts on the lights to check his surroundings. Discovering that his symptoms are not geographically dependent, mean that moving house would not resolve his symptoms.

Psychological counselling to assist with resolving ongoing trauma triggers is a reasonable public expectation to assist survivors to make a complete recovery as quickly as possible from a disaster. Further research is recommended to quantify the potential burden of psychological harm to people affected by natural disasters and to explore effective and economically viable methods for addressing this public health problem.

\section{Inadequate access to psychological care}

The inadequacy of psychological care was most evident in Grantham where 13 people died in a small community of about 300 people. The effectiveness of the counselling team in Grantham was the only one evaluated because an Inquiry was held in 2015 into the disaster in Grantham. Witnesses told the Inquiry that a team of counsellors was sent in a week after the disaster. A second, different team, arrived the following week and a third, different team, the third week. A Grantham business woman told the inquiry that survivors who had seen a counsellor in the first two weeks did not go back in the third week. The counselling service was then stopped because no one wanted to see them. Cancellation of the service meant that deeply-affected survivors became reluctant to seek alternative help and felt stigmatised if they sought psychological care.

Publicly-funded, routine psychological care of disaster survivors would 
help to diminish the sense of stigma of seeking psychological help by making psychological 'first aid' a socially-acceptable and ordinary aspect of post-disaster care. Further research is recommended to establish benchmarks for post-disaster counselling programs to ensure the services offered are fit for purpose.

\section{Being trapped in the disaster zone due to depressed property values}

Property values in the towns and districts affected by the flash flood fell dramatically and immediately. In Murphys Creek, a householder said the decision to stay was forced upon them because their unfinished, flooded house was not saleable after the flood.

We hadn't completed the building when the flood came so it wasn't really a saleable item at that point. We thought we could just walk away and leave everything. We are not millionaires - but also we had bought this land with a purpose and we still felt the purpose was valid. We liked it. We still had that dream alive enough to rebuild.

Many people were trapped in locations connected with their memory of the traumatic events of the day of the flood and more than five years later, they were still enduring daily triggers of the trauma because they could not afford to move from the flood zone. So, even though their houses had been repaired, their property values were likely to remain low for an extended time.

People who took the costlier but health-preserving decision to leave the flood zone reported that they believed they were able to recover their physical and mental health sooner than if they had remained in the disaster zone. The benefit of leaving was reportedly derived from the reduction in environmental triggers to the memories of the trauma on the day of the flood. One survivor commented that he believed he would not be alive still if he had not moved when he did because of the effect of stress on his heart that had required an operation.

Publicly-funded support for people whose lives were endangered during a disaster would seem a reasonable expenditure of public money depending on appropriate eligibility criteria. Further research is recommended to establish eligibility criteria, costs and benefits and to establish a pilot project so that a cost-benefit analysis can be undertaken.

\section{Carrying house insurance risk due to inflated house insurance premiums}

At the same time that real estate values plummeted, house holders were shocked to discover they were not covered for floods and those who were insured experienced steep rises in their insurance premiums (Natural Disaster Insurance Review: Inquiry into flood insurance and related matters 2011). A federal government review of house insurance made 47 recommendations to improve household insurance cover for floods (Figure 1).

In Helidon, where some houses were struck by very fast-moving dangerous flood- 
water deeper than their gutters, premiums rose to unaffordable levels. For example, Lloyd and Jean Warr saw their insurance premium rise to more than $\mathrm{A} \$ 34,000$ per year after the flood — an amount they could not afford. They rebuilt in the same location but included an indoor ladder to the ceiling and a trapdoor onto the roof (Figure 2).

Further research is recommended to ensure that householders in locations that have been flooded are provided with economically viable options to move away from the flood zone or to gain access to affordable house insurance.

\section{Conclusion}

The in-depth interview data from the 30 interviewees in this study indicates that many people were demonstrably worse off after five years than they had been in the first year after the disaster. Initial as-

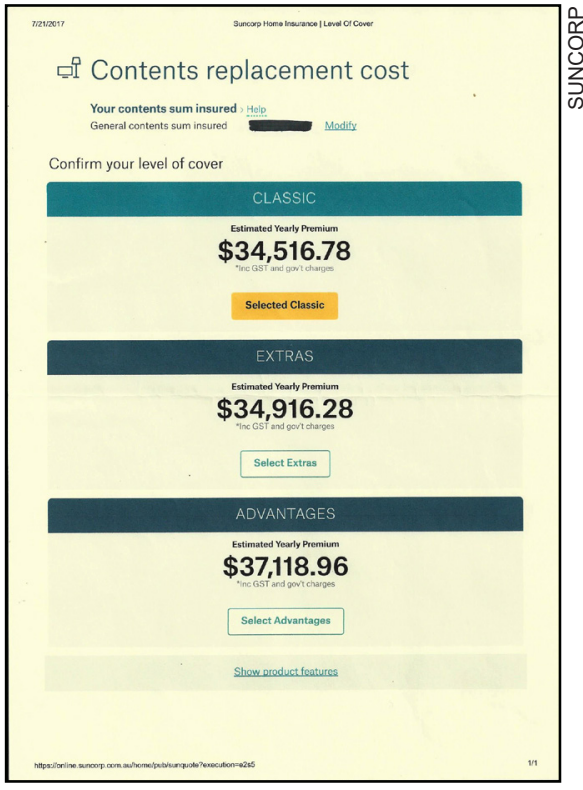

Figure 1. Post-flood annual house insurance premium quotes following the 2011 flash flood disaster in the Lockyer Valley in south east Queensland. sistance with emergency food and accommodation gave way to often intractable difficulties with housing, insurance, employment and chronic physical and mental health conditions. Media coverage of the event was extensive immediately after the event but dwindled over the years even though the problems being experienced by survivors were becoming worse. Lack of media coverage gave an impression that survivors had recovered when they were still seriously affected after five years, by a range of factors:

- bereavement of a spouse, child or close friend during or post-disaster;

- delayed shock due to their own near-drowning;

- shock caused by near-deaths of family members;

- loss of employment;

- loss of physical ability to return to their pre-disaster employment;

- loss of community cohesion;

- ongoing trauma triggers of the disaster event;

- inadequate access to psychological care;

- being trapped in the disaster zone due to depressed property values; and

- being unable to afford to insure their house and therefore facing a total loss in a subsequent flash flood. 


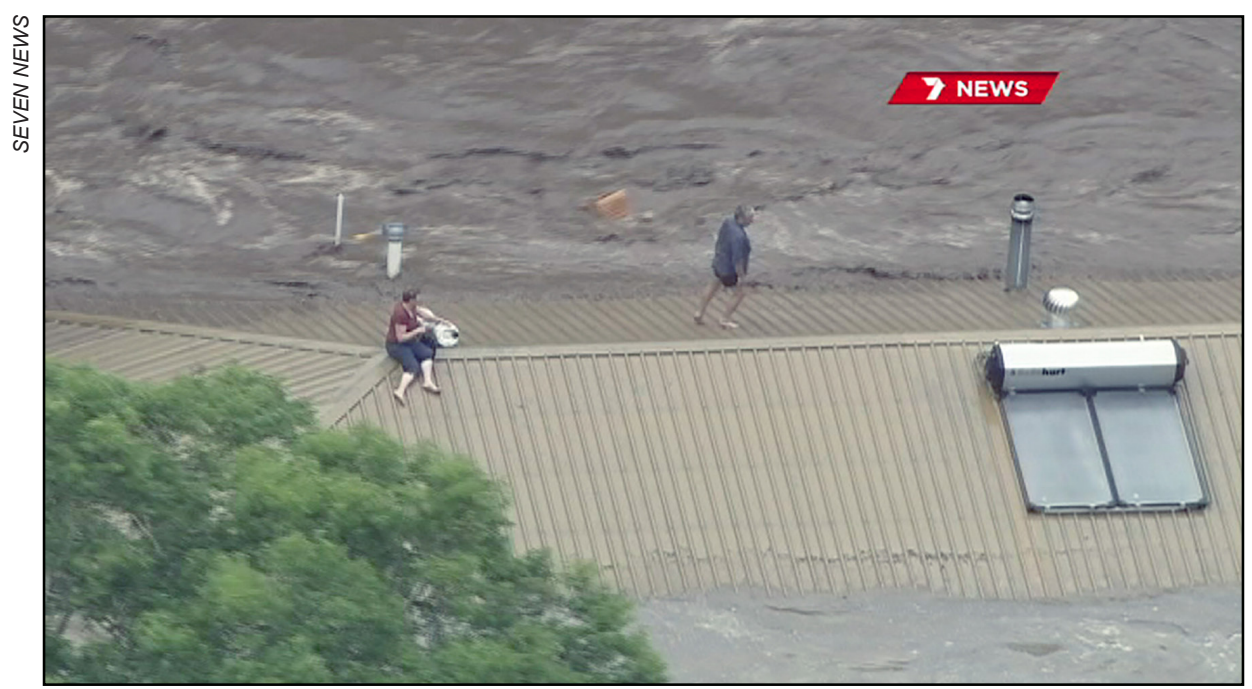

Figure 2. Lloyd and Jean Warr on their roof at Helidon in the Lockyer Valley, 10 January 2011.

In many cases a combination of these difficulties overloaded survivors and meant those people who had been most severely affected by the disaster were unlikely to be able to recover their pre-flood situation and they were forced to adapt to a 'new normal' that might include protracted health problems, unemployment, homelessness or living in continual danger of a repeat deadly flood.

Disaster recovery focuses primarily on macro-recovery of national and state infrastructure. Personal and community recovery is largely addressed by ad hoc public appeals and government announcements, ad hoc and changing eligibility criteria for assistance and a lack of legislated principles for providing publicly-funded support. The unexpected and unprecedented nature of the 2011 flash flood disaster in South East Queensland meant that recovery plans were inadequate to address the complex needs of the victims. The combination of difficulties faced by survivors of this disaster created a complex of problems for individuals and families that were insurmountable to many people. The findings of this study indicate that consideration should be given to a public policy initiative that will provide financial support in a similar way to the current welfare schemes applied to workers who are injured and who need emergency medical care, rehabilitation, retraining and other supports in order to expedite their physical and mental recovery and return to the workforce. Further research is recommended into which aspects of disaster recovery are the most urgent priorities. Research is also needed to assess the viability of providing publicly-funded assistance to help victims obtain medical care, emergency housing, employment and other needs. The findings of this study have immediate practical application for governments, policy makers, disaster recovery experts, insurance companies, emergency housing providers, employer associations and post-disaster medical care. 


\section{References}

Alesch, D. (2005). Complex urban systems and extreme events: Toward a theory of disaster recovery Proceedings of the 1 st international conference on urban disaster reduction. Kobe, Japan.

Bligh, A. (2011). All is in place for Saturday's historic Grantham land ballot [Press release]

Boulter, S., Palutikof, J., Karoly, D., \& Guitart, D. (2013). Natural disasters and adaptation to climate change. Cambridge, UK: Cambridge University Press.

Coates, L. (2012, January 10). Moving Grantham? Relocating flood-prone towns is nothing new. The Conversation. Retrieved from theconversation.com/moving-granthamrelocating-flood-prone-towns-is-nothing-new-4878

Comfort, L., Birkland, T., Cigler, B., \& Nance, E. (2010). Retrospectives and prospectives on Hurricane Katrina: Five years and counting. Public Administration Review, 70(5), 669-678.

Cox, R. S., Long, B. C., Jones, M. I., \& Handler, R. J. (2008). Sequestering of suffering: Critical discourse analysis of natural disaster media coverage. Journal of Health Psychology, 13(4), 469-480.

Daniels, R., Kettl, D., \& Kunreuther, H. (Eds.). (2006). On risk and disaster: Lessons from Hurricane Katrina. Philadelphia, PA: University of Pennsylvania Press.

Garnett, J. D., \& Moore, M. (2010). Enhancing disaster recovery: Lessons from exemplary international disaster management practices. Journal of Homeland Security and Emergency Management, 7(1), Article 40.

Gearing, A. (2011). The day that changed Grantham (55 min). [Audio documentary]. ABC Radio National 360 Documentaries.

Gearing, A. (2012a). Amanda Gearing: Queensland flood collection 2011-2012. Brisbane: Queensland State Library

Gearing, A. (2012b). Lessons from media reporting of natural disasters: A case study of the 2011 flash floods in Toowoomba and the Lockyer Valley. Unpublished masters degree thesis, Queensland University of Technology, Brisbane.

Gearing, A. (2012c). The Torrent: Toowoomba and Lockyer Valley, January 2011. Brisbane: University of Queensland Press.

Gearing, A. (2017). The Torrent: A true story of heroism and survival. Brisbane: University of Queensland Press.

Haas, J. E., Kates, R., \& Bowden, A. M. (Eds.). (1977). Reconstruction following disaster. Cambridge, MA, and London, UK: MIT Press.

Hydrologic Research Center. (2018). HRC global initiative on flash floods.

Johnson, L., \& Hayashi, H. (2012). Synthesis efforts in disaster recovery research. International Journal of Mass Emergencies and Disasters, 30(2), 212-238.

Letcher, T. M. (2009). Climate change: Observed impacts on planet earth (First Ed.). Amsterdam; Boston, MA: Elsevier.

Mileti, D. S. (1999). Disaster by design: A reassessment of natural hazards in the United States. International Decade for Natural Disaster Reduction. Washington, DC: Joseph Henry Press.

Natural Disaster Insurance Review: Inquiry into flood insurance and related matters (2011). Canberra: Australian Government.

Newman, E., \& Nelson, S. (2012). Reporting on resilience and recovery in the face of disaster and crime: research and training implications. Australian Journalism Review, 34(1), 17-32. Retrieved from search.informit.com.au/documentSummary; $d n=61241$ 8108548269;res=IELLCC

Rubin, C. (1985). Community recovery from a major natural disaster. (Monograph No. 41). 
Boulder, CO: University of Colorado.

Sanders, B. (2011). First Grantham home welcomed to new estate (Vol. 22, November, 2011). ABC Radio, Toowoomba. www.abc.net.au.

Tatsuki, S. (2007). Long-term life recovery processes among survivors of the 1995 Kobe earthquake: 1999, 2001, 2003, and 2005 Life recovery social survey results. Journal of Disaster Research, 2(6), 484-501.

Uscher-Pines, L. (2008). Health effects of relocation following disaster: a systemic review of the literature. Disasters, 33(1), 1-22.

\section{Acknowledgement}

The author is grateful to the many survivors and rescuers of the 2011 disaster who were willing to speak in 2011 and again in 2016 about their experiences.

Dr Amanda Gearing is an Australian investigative journalist, author and broadcaster. Her work has led to law reform and to various inquiries in Australia and Britain. She has won many awards for her print and broadcast journalism including a Walkley Award in 2012. She completed her doctorate in journalism in 2016. gearingap@bigpond.com

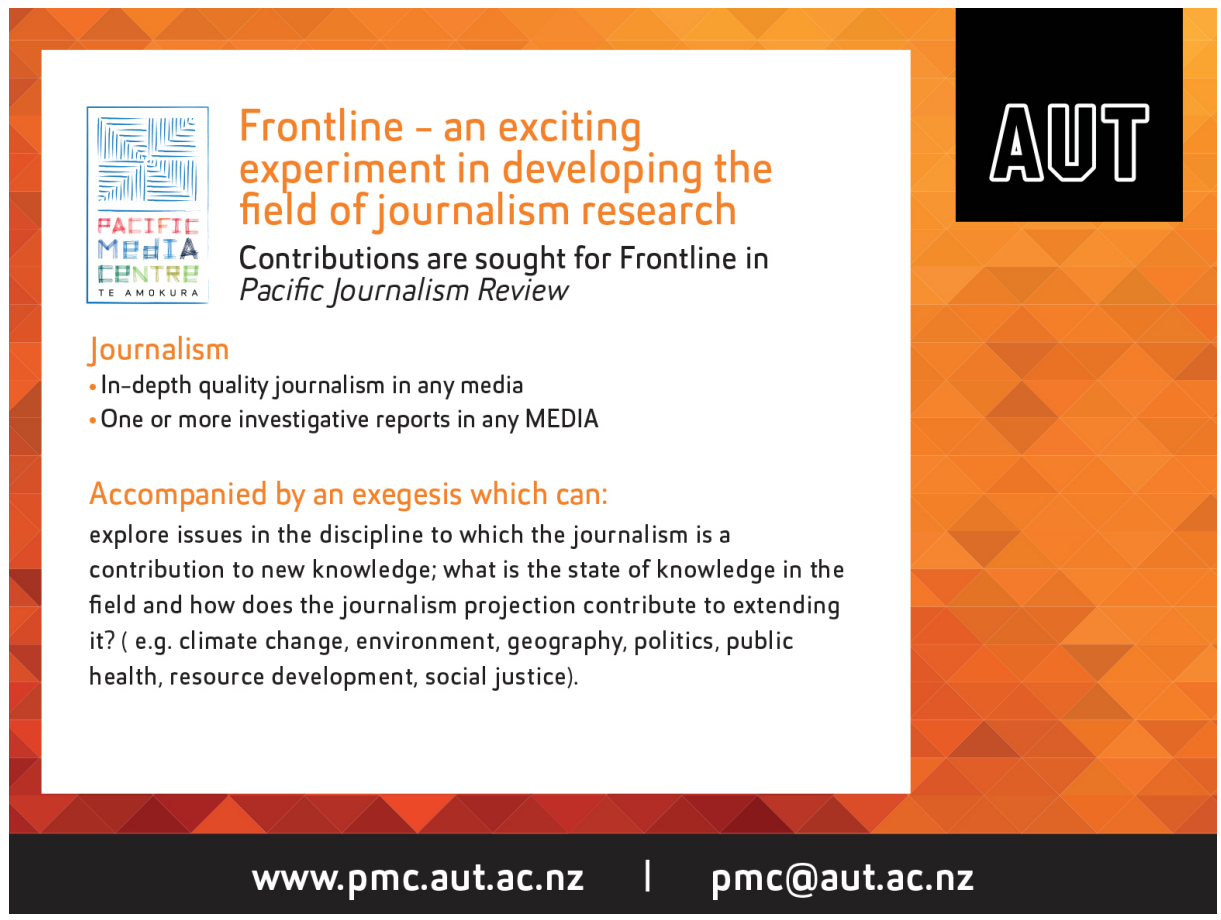

